\title{
Validação de método de cromatografia líquida para a determinação de sete ácidos graxos voláteis intermediários da digestão anaeróbia
}

\section{Validation of a liquid chromatography methodology for the analysis of seven volatile fatty acids intermediates of anaerobic digestion}

\author{
Patrícia da Luz Mesquita \\ Doutoranda em Engenharia Metalúrgica, de Materiais e de Minas pela Universidade Federal de Minas Gerais (UFMG) \\ Mestre em Engenharia Ambiental pela Universidade Federal de Ouro Preto (UFOP) - Ouro Preto (MG), Brasil. \\ Professora do Departamento de Engenharia Química e Estatística da Universidade Federal de São João Del-Rei, Campus Alto Paraopeba - \\ Ouro Branco (MG), Brasil.
}

\section{Robson José de Cássia Franco Afonso}

Ph.D. em Química (Royal Holloway College). Professor Adjunto do Departamento de Química da UFOP, Campus Morro do Cruzeiro - Ouro Preto (MG), Brasil.

\section{Sérgio Francisco de Aquino}

Ph.D. em Engenharia Química (Imperial College London). Professor Adjunto do Departamento de Química da UFOP, Campus Morro do Cruzeiro - Ouro Preto (MG), Brasil.

\section{Gustavo de Sousa Leite}

Graduado em Química Industrial e Mestre em Engenharia Ambiental pela UFOP, Campus Morro do Cruzeiro - Ouro Preto (MG), Brasil.

\section{Resumo}

Ácidos graxos voláteis (AGV) são importantes compostos intermediários indicadores da digestão anaeróbia. Este artigo apresenta dados de validação de uma metodologia para análise de uma mistura de sete AGV (C1 a C5) em amostras ambientais por cromatografia líquida de alta eficiência (CLAE). Foi utilizada uma coluna de exclusão iônica a $55^{\circ} \mathrm{C}$, volume de injeção de $10 \mu \mathrm{L}$ e fase móvel $\left(0,01\right.$ mol. $\left.\mathrm{L}^{-1} \mathrm{H}_{2} \mathrm{SO}_{4}\right)$ a 0,6 mL.min ${ }^{-1}$. Os critérios de validação foram: limites de detecção e de quantificação, que ficaram na faixa de 5,0 a $10 \mathrm{mg} \cdot \mathrm{L}^{-1}$ e 15 a $30 \mathrm{mg} \cdot \mathrm{L}^{-1}$, respectivamente; linearidade (comprovada para todos os ácidos); repetitividade e sensibilidade (muito boa para a maioria dos ácidos); efeito de matriz (efeito de supressão observado para o ácido isobutírico) e exatidão (85 a 104\%). Sendo assim, as condições operacionais adotadas se mostraram válidas para a quantificação de AGV em efluentes de reatores anaeróbios.

Palavras-chave: ácidos graxos voláteis; cromatografia líquida de alta eficiência; validação de método de análise.

\begin{abstract}
Volatile fatty acids (VFA) are important intermediate compounds that somehow indicate the efficiency of anaerobic systems. This paper presents results of method validation for seven VFA (C1 to C5) analysis in environmental samples by high performance liquid chromatography (HPLC). It was used an ion exclusion column kept at $55^{\circ} \mathrm{C}$; injection volume of $10 \mu \mathrm{L}$ and mobile phase $\left(0.01 \mathrm{~mol} \cdot \mathrm{L}^{-1} \mathrm{H}_{2} \mathrm{SO}_{4}\right)$ at $0.6 \mathrm{~mL} \cdot \mathrm{min}^{-1}$. The validation criteria adopted were: limits of detection and quantification, that fell in the ranges of $5.0-10 \mathrm{mg} \cdot \mathrm{L}^{-1}$ and $15-30 \mathrm{mg} \cdot \mathrm{L}^{-1}$, respectively; linearity (verified for all acids); repeatability and sensibility (very good for most acids); matrix effect (suppression effect observed for isobutyric acid) and accuracy (from 85 to 104\%). Therefore, the operational conditions adopted seemed to be adequate and valid to measure VFA in samples from anaerobic reactors.
\end{abstract}

Keywords: volatile fatty acids; high performance liquid chromatography; analysis method validation. 


\section{Introdução}

Os ácidos graxos voláteis (AGV) são ácidos orgânicos de cadeia curta, de baixo peso molecular, de elevado caráter hidrofílico, e que apresentam valores de pKa que variam de 3,75 a 4,87. Os AGV que contém de 1 a 5 carbonos são comumente denominados ácidos fórmico $(\mathrm{C} 1)$, acético (C2), propiônico (C3), butírico (C4), isobutírico (C4), valérico (C5) e isovalérico (C5), e apresentam-se predominantemente dissociados em meios cujos valores de $\mathrm{pH}$ sejam maiores que os respectivos valores de pKa. Em função disso, é comum na literatura da engenharia sanitária e ambiental se referir a tais compostos pelo nome do sal correspondente (ex.: acetato, propionato).

Os AGV são os principais intermediários da digestão anaeróbia de compostos orgânicos presentes em resíduos e efluentes. Como em condições anaeróbias os microrganismos não dispõem de um aceptor final de elétrons (tal qual o oxigênio nos processos aeróbios), o substrato orgânico é ao mesmo tempo utilizado como aceptor e doador de elétrons, ou seja, uma parte do composto orgânico poluente é oxidada enquanto outra parte é reduzida, no processo conhecido como fermentação. Segundo Rittmann e McCarty (2001), durante a fermentação de matéria orgânica por culturas mistas encontradas no tratamento de esgotos e resíduos, a formação de AGV é preferencial à do etanol porque os microrganismos dominantes são geralmente aqueles que encontraram as melhores rotas para obtenção de energia disponível nas condições impostas.

Em um reator estável, operado sob condições ótimas de crescimento microbiano e na ausência de fatores de estresse, as etapas acidogênica, acetogênica e metanogênica ocorrerão em passos similares, de forma a haver uma equalização nas taxas de produção e consumo dos AGV. Contudo, mudanças de condições ambientais (temperatura, ausência temporária de nutrientes, presença temporária de compostos tóxicos) e operacionais (choques de carga orgânica ou hidráulica) podem resultar no acúmulo de AGV devido a limitações cinéticas ou termodinâmicas (AQUINO \& CHERNICHARO, 2005). Dessa forma é importante monitorar a concentração de AGV nos reatores anaeróbios como forma de prevenir problemas operacionais e/ou subsidiar ações corretivas em sistemas desbalanceados. Além disso, a especiação dos AGV, ou seja, a determinação da concentração individual de cada ácido é importante para diagnosticar o grupo de microrganismos mais afetado pelas condições adversas.

Entre os AGV potencialmente formados em reatores anaeróbios, os ácidos fórmico, acético e propiônico merecem destaque. O ácido acético é o mais importante AGV uma vez que é precursor direto dos microrganismos metanogênicos acetoclásticos, que contribuem com cerca de $70 \%$ do metano produzido biologicamente (AQUINO \& CHERNICHARO, 2005). O ácido propiônico é outro intermediário comum do metabolismo de açúcares, proteínas, ácidos orgânicos de cadeia longa e compostos orgânicos mais complexos, podendo responder por até $20 \%$ do fluxo de elétrons canalizado para a produção de metano (SPEECE, 1996). Baixas concentrações de propionato são indicativas de um bom funcionamento do processo anaeróbio, ao passo que o acúmulo de tal intermediário normalmente reflete um desequilíbrio entre as etapas metabólicas que governam a digestão anaeróbia. Por sua vez, o ácido fórmico é o mais simples dos AGV e tem sido relatado como importante intermediário formado na degradação de compostos orgânicos complexos ou sob condições de estresse (ZAHER et al., 2006; VOOLAPALI \& STUCKEY, 2001). Além disso, a metanogênese é mais rápida a partir de formiato do que acetato, e independe da concentração de gás hidrogênio dissolvido no meio, sendo por isso a rota preferida por microrganismos metanogênicos capazes de efetivarem a redução do formiato. Segundo Speece (1996), o ácido fórmico é de difícil detecção por cromatografia gasosa com detecção por ionização de chama (CG-DIC), o que resultou, por muitos anos, em escassez de informação sobre a concentração de tal composto em sistemas anaeróbios.

Outro aspecto importante relacionado à presença de AGV em efluentes anaeróbios e anóxicos é que eles contribuem diretamente para a demanda química de oxigênio (DQO), de forma que o aumento da eficiência da digestão anaeróbia passa pela degradação e redução da concentração de tais metabólitos. Sendo assim, o monitoramento da concentração individualizada dos AGV em sistemas anaeróbios é importante para avaliar se a DQO residual é causada pelo acúmulo de tais compostos (MESQUITA et al., 2010; CORRÊA, 2009), o que refletiria uma condição de estresse; devido à recalcitrância de compostos presentes no afluente ou a produtos microbianos (PMS) gerados durante o tratamento. Segundo Ábalos et al. (2000), a presença de AGV em sistemas de tratamento de efluentes contribui ainda para a geração de odor desagradável, juntamente com aminas e substâncias sulfurosas. Além disso, a remoção biológica de fósforo e nitrogênio em sistemas de lodos ativados também pode envolver a participação dos AGV, o que justifica o crescente interesse na determinação correta de tais compostos intermediários (RANDALL et al., 1997; EILERSEN et al., 1995).

Diversos procedimentos já foram desenvolvidos para a análise de AGV, tais como os métodos potenciométricos e condutimétricos que permitem a quantificação total de AGV (RIBAS et al., 2007), e métodos cromatográficos (de fase gasosa ou líquida) que permitem a especiação dos AGV presentes. Há ainda metodologias de análise de AGV por eletroforese capilar com detecção UV-Vis; fluorescência induzida por laser (ZURIGUEL et al., 1997); análise de injeção em fluxo (AIF) (RIBAS et al., 2007), que são técnicas menos usadas que àquelas previamente mencionadas.

No caso de emprego de cromatografia de fase gasosa, a amostra deve ser inicialmente preparada para extrair os AGV do meio aquoso. Os procedimentos usados para tal finalidade incluem extração líquido-líquido em meio previamente acidificado (MORAES et al., 2001; MANNI \& CARON, 1995); destilação (MORAES et al., 2001); purga e aprisionamento (CLARK \& BUNCH, 1997) e microextração em fase sólida (ÁBALOS et al., 2000). O uso de cromatografia de fase 
gasosa tem como principal inconveniente a necessidade de extração dos AGV da amostra aquosa, o que, além de aumentar o tempo de análise, usualmente requer o uso de solventes orgânicos controlados (ex.: éter metil ter butílico - EMTB) ou clorados (ex: diclorometano). Além disso, como os solventes não clorados (ex.: éter metílico) dão boa resposta nos detectores de ionização de chama, há a possibilidade dos ácidos de menor cadeia (ex.: fórmico) serem coeluídos da coluna no tempo de retenção do solvente, conforme relatado por Speece (1996).

O uso de cromatografia líquida de alta eficiência (CLAE) permite a análise direta (após simples filtração) das amostras com excelente resolução dos principais AGV em equipamentos providos de detectores de uso comum (ex.: UV-Vis). Nesse caso, podem ser utilizadas colunas de troca iônica (RIBAS et al., 2007) ou de fase reversa (CERQUEIRA et al., 2011), com detectores de condutividade (MORAES et al., 2001) ou, mais comumente, com espectrometria de absorção na região do ultravioleta (SANTOS et al., 2010; RIBAS et al., 2007; AQUINO \& STUCKEY, 2004).

Independente da metodologia de análise empregada, é importante que ela seja devidamente validada, uma vez que a validação garante qualidade metrológica dos ensaios e confiabilidade técnica dos resultados obtidos. A revisão da literatura mostra que poucos trabalhos relatam a utilização de métodos validados para o monitoramento de reatores biológicos, o que muitas vezes coloca sob suspeita os resultados e as discussões apresentadas. Tendo em vista a importância do monitoramento individualizado dos ácidos orgânicos intermediários da digestão anaeróbia, o objetivo deste trabalho foi o desenvolvimento de uma metodologia que emprega a utilização de cromatografia líquida de alta eficiência com detecção por absorção no UV-Vis usando arranjo de diodos (CLAE-DAD) para análise dos sete principais AGV em efluentes anaeróbios.

\section{Metodologia}

A mistura de ácidos graxos voláteis (AGV) foi preparada a partir dos ácidos fórmico, acético, propiônico, isobutírico, butírico, isovalérico e valérico, todos adquiridos da Sigma-Aldrich, com grau de pureza que variou de 99,5 a 99,9\%. As análises foram realizadas em sistema de cromatografia líquida de alta eficiência (CLAE) da Shimadzu, usando uma coluna de troca iônica Aminex HPX-87H (Bio-Rad, $300,0 \times 7,8 \mathrm{~mm}$ ), a $55^{\circ} \mathrm{C}$. A fase móvel empregada foi solução de ácido sulfúrico (Sigma-Aldrich) 0,01 mol.L-1 ${ }^{-1}$ no modo isocrático com uma vazão de 0,6 mL.min ${ }^{-1}$, empregando-se volume de injeção de $10 \mu \mathrm{L}$. Os AGV foram analisados no comprimento de onda de $210 \mathrm{~nm}$ com detector UV-Vis com arranjo de diodos (DAD - Shimadzu SPDM20A) em um tempo total de análise de 35 min. Todos os reagentes usados foram de grau PA, sendo suas soluções preparadas com água deionizada ultrapura (Tipo I).

Para a identificação dos analitos no cromatograma, uma análise individual foi feita, com base nos tempos de retenção de cada um. Para se avaliar o efeito de matriz, amostras de efluente de reator anaeróbio de bancada (MESQUITA et al., 2010) foram usadas, as quais foram previamente centrifugadas (3.500 rpm, 10 min, Centrífuga Excelsa II, 206-BL, Fanem) com posterior filtração em membrana (acetato de celulose, porosidade de 0,45 $\mu \mathrm{m}$, Millipore) para remoção de sólidos suspensos. $\mathrm{O}$ procedimento de preparo da amostra não resultou na alteração de $\mathrm{pH}$ da amostra. Para todas as análises descritas neste artigo, as amostras foram apenas filtradas para a remoção de sólidos suspensos, ou seja, o método proposto não requer nenhuma etapa de extração ou concentração dos AGV da amostra.

A validação da metodologia de análise dos AGV foi realizada por meio dos seguintes critérios, conforme preceitos da Resolução ANVISA RE no 899, de 29 de maio de 2003 e documento INMETRO DOQCGCRE-008, de 2006: limite de detecção, limite de quantificação, faixa de trabalho, linearidade, precisão (repetitividade), sensibilidade, seletividade e exatidão, usando soluções em várias concentrações.

Para a determinação dos limites de detecção (LD) e de quantificação (LQ), uma solução-padrão estoque da mistura de ácidos com concentração de 400 mg.L.-1 foi preparada, a partir dos ácidos puros, e as demais concentrações foram obtidas por diluição. Foram injetadas amostras-padrão preparadas em diferentes concentrações. Os relatórios gerados foram programados para especificarem a relação sinal/ruído da análise. Com base nesses resultados, padrões de concentrações mais diluídas foram sendo preparados até ser atingido o valor sinal/ruído aproximado de 3 para LD e 10 para LQ (HARTMANN et al., 1998; LANÇAS, 2004).

Para a determinação do intervalo dinâmico (ou faixa dinâmica), soluções-padrão da mistura de ácidos foram preparadas em diferentes concentrações, partindo do limite de quantificação. As concentrações foram 12,$5 ; 25,0 ; 50,0 ; 100,0 ; 200,0 ; 400,0 ; 700,0 ; 1.000,0 ; 1.500,0$ e 2.000,0 mg. $\mathrm{L}^{-1}$. Os dados para a determinação da linearidade foram obtidos a partir das mesmas amostras injetadas para determinar a precisão, em sete replicatas por concentração. As concentrações escolhidas foram 12,5; 25,0; 50,0; 100,0; 200,0 e 400,0 mg..-1 da mistura de ácidos, atendendo assim a demanda mínima recomendada de 5 pontos para a curva analítica (LANÇAS, 2004). Foi feita análise de regressão por mínimos quadrados e a correlação foi obtida por meio do coeficiente de determinação $\mathrm{R}^{2}$.

A avaliação da precisão do método foi feita neste trabalho com base na repetitividade. Sete replicatas de solução padrão de $200 \mathrm{mg} \cdot \mathrm{L}^{-1}$ (concentração intermediária da curva analítica) foram preparadas pelo mesmo analista, e foram analisadas em sequência e sob as mesmas condições operacionais. As médias e os desvios-padrão foram obtidos com vistas a se determinar a precisão a partir do coeficiente de variação (CV), conforme a Equação 1:

\section{$\mathrm{CV}=\mathrm{DP} / \mathrm{CMPx} 100$}

em que:

$\mathrm{DP}=$ desvio padrão

$\mathrm{CMD}=$ concentração média determinada 
A sensibilidade de um método indica sua capacidade de discriminar, com uma fidelidade estabelecida, concentrações próximas de um analito. A sensibilidade pode ser determinada por intermédio da inclinação da curva analítica, uma vez que quanto maior a absortividade da substância, maior o coeficiente angular e mais sensível é o método. Para cada curva analítica construída para a avaliação da linearidade, foi avaliado o coeficiente angular obtido a partir da análise regressão linear, o que permite comparar a sensibilidade do método para cada AGV.

Segundo Lanças (2004), a seletividade corresponde à capacidade de um método em determinar o analito de maneira inequívoca na presença de outras substâncias susceptíveis de interferirem na determinação. No presente estudo, a seletividade foi avaliada pelos tempos de retenção dos analitos nos cromatogramas obtidos com água destilada e efluente anaeróbio fortificado e pelo uso do sistema de detecção UVVis com arranjo de diodos, que permite a obtenção de um espectro de absorção em toda a região do UV-Vis para cada pico eluído.

A adição padrão foi o método adotado neste estudo para avaliar a exatidão, pois ele se aplica quando for difícil ou impossível preparar um branco da matriz sem a substância de interesse (RIBANI et al., 2004), o que é o caso. Para o cálculo da exatidão, duas informações são necessárias: o valor real (aquele tido como verdadeiro; neste caso, corresponde à concentração do padrão preparado para a fortificação da matriz) e o valor obtido (que é aquela concentração obtida pela curva analítica a partir da resposta de intensidade do pico). Contudo, após a obtenção das respostas, foi necessário determinar a concentração de cada ácido na matriz original, uma vez que esta não era isenta dos analitos. Para tanto, foi feita uma curva analítica com adição de padrão nas concentrações de 25, 50, 100, 200, 500 e 1.000 mg. $\mathrm{L}^{-1}$, e a análise em triplicata. Por meio da extrapolação da curva, a intercessão com o eixo x proveu a informação, anteriormente desconhecida, da concentração de cada ácido presente na matriz original (RIBANI et al., 2004). Esse valor foi então deduzido da concentração total, proveniente de uma curva analítica dos padrões isentos da matriz (calibração externa), usando as respostas da matriz fortificada, sendo a diferença utilizada como valor obtido. Segundo Lanças (2004), a exatidão pode ser determinada pela expressão dada na Equação 2. Os cálculos de todos os parâmetros de validação foram feitos nos programas Microsoft Excel 2010 e Croma Validate.

Exatidão $=[1-(\mathrm{Vr}-\mathrm{Vd}) / \mathrm{Vr}] \times 100$

em que:

$\mathrm{Vr}=$ valor real, aquele tido como verdadeiro

$\mathrm{Vd}=$ valor desejado, ou obtido pela curva analítica

\section{Resultados e Discussão}

Na Figura 1, é apresentado um cromatograma obtido com o método desenvolvido, em duas diferentes matrizes, água deionizada e efluente de reator anaeróbio, que receberam solução padrão de AGV de forma que a concentração final de cada ácido fosse $400 \mathrm{mg} \cdot \mathrm{L}^{-1}$. Percebe-se que praticamente não houve deslocamento do tempo de retenção dos analitos em matriz complexa (efluente anaeróbio). Da mesma forma, a resolução dos picos parece não ter sido afetada pelos componentes da matriz (efluente anaeróbio). A comparação dos

Figura 1 - Cromatograma típico de amostras de efluente anaeróbio e água deionizada (ultrapura) fortificados com padrão de ácidos graxos voláteis $\left(400 \mathrm{mg} \cdot \mathrm{L}^{-1}\right)$. 
tempos de retenção dos analitos e os espectros obtidos no sistema UV-Vis com arranjo de diodos, permitem afirmar que o método foi seletivo para todos os sete AGV analisados.

$\mathrm{Na}$ Tabela 1, apresentam-se os tempos de retenção para cada ácido da mistura de AGV obtidos nos cromatogramas mostrados na Figura 1

\section{Limites de Detecção e Quantificação}

O limite de detecção é a menor concentração de um analito que pode ser, com segurança, diferenciado do ruído instrumental (LANÇAS, 2004). A literatura relata que um procedimento comum é aceitar como LD a concentração do analito que produz um sinal três vezes maior que o ruído do sistema (HARTMANN et al., 1998). Já o limite de quantificação corresponde à menor quantidade de um analito que pode ser quantificada com exatidão. Valores aproximadamente dez vezes maiores que o desvio-padrão do sinal gerado empregando-se um branco são aceitos como LQ, ou seja, aproximadamente três vezes o LD (LANÇAS, 2004). A Tabela 2 apresenta os resultados obtidos das relações sinal/ruído para cada analito estudado.

Tabela 1 - Tempos de retenção aproximados para cada ácido graxo volátil presente na mistura nas amostras de efluente anaeróbio e do branco.

\begin{tabular}{lcc|} 
& \multicolumn{2}{c}{ Tempo de retenção (min) } \\
\cline { 2 - 3 } Analito & Branco & Efluente anaeróbio \\
\hline Ácido fórmico & 13,5 & 13,5 \\
\hline Ácido acético & 14,5 & 14,5 \\
\hline Ácido propiônico & 17,2 & 17,2 \\
\hline Ácido isobutírico & 19,5 & 19,5 \\
\hline Ácido Butírico & 21,2 & 21,2 \\
\hline Ácido isovalérico & 24,6 & 24,6 \\
\hline Ácido valérico & 30,2 & 30,2 \\
\hline
\end{tabular}

Tabela 2 - Relação sinal/ruído obtida para cada analito na mistura de ácidos graxos voláteis.

\begin{tabular}{|lccc|}
\hline & \multicolumn{3}{c|}{ Relação sinal/ruído } \\
\cline { 2 - 4 } Analito & $\begin{array}{c}\text { Padrão } \\
5,0 \mathrm{mg} \cdot \mathrm{L}^{-1}\end{array}$ & $\begin{array}{c}\text { Padrão } \\
6,25 \mathrm{mg} \cdot \mathrm{L}^{-1}\end{array}$ & $\begin{array}{c}\text { Padrão } \\
\text { Ácido fórmico }\end{array}$ \\
\hline Ácido acético & 3,0 & 10,0 & 16,1 \\
\hline Ácido propiônico & 3,7 & 5,5 & 8,3 \\
\hline Ácido isobutírico & 3,5 & 4,6 & 6,2 \\
\hline Ácido butírico & 3,1 & 6,1 & 7,8 \\
\hline Ácido isovalérico & 2,8 & 3,2 & 5,5 \\
\hline Ácido valérico & 2,5 & 2,9 & 4,7 \\
\hline
\end{tabular}

N/D: Não detectado.
Para a solução de concentração 5,0 mg. $\mathrm{L}^{-1}$, as relações sinal/ruído dos ácidos isovalérico e valérico são inferiores a 3,0. Para o ácido butírico, essa relação ficou próxima a 3,0, e para os demais, acima de 3,0, logo essa concentração foi considerada o LD para esses analitos. Como a relação sinal/ruído na solução de concentração $6,25 \mathrm{mg} . \mathrm{L}^{-1}$ para o ácido isovalérico foi 2,9, valor próximo de 3,0, considera-se esse sendo seu LD. O ácido valérico só apresentou valor de sinal/ruído satisfatório na concentração igual a $10 \mathrm{mg} . \mathrm{L}^{-1}$, logo esse foi o valor tomado como LD para esse analito. A Tabela 3 sistematiza os valores de LD e LQ para os analitos deste estudo.

Cerqueira et al. (2011) obteve valores de LD menores do que os aqui obtidos para os ácidos acético e propiônico, e igual para o ácido butírico, o que indica que o método desenvolvido por eles seria mais adequado para análise desses dois analitos, quando em concentrações da ordem de $10 \mathrm{mg}$. $\mathrm{L}^{-1}$. Para amostras que contenham concentrações superiores, ambas as metodologias são equiparáveis.

\section{Linearidade}

A linearidade é a resposta obtida em função da concentração do analito, a qual deve ser estudada na faixa de trabalho. A linearidade é função da natureza química do analito e do tipo de detector utilizado. A Tabela 4 mostra os coeficientes de correlação linear dos analitos estudados, os quais foram sempre maiores que 0,99 comprovando a linearidade do método na faixa de 25 a $1.000 \mathrm{mg} . \mathrm{L}^{-1}$.

Tabela 3 - Valores de limite de detecção e limite de quantificação obtidos para cada ácido graxo volátil.

\begin{tabular}{|lcc|}
\hline Analito & $\begin{array}{c}\text { Limite de } \\
\text { detecção }\left(\mathrm{mg} \cdot \mathrm{L}^{-1}\right)\end{array}$ & $\begin{array}{c}\text { Limite de } \\
\text { quantificação }\left(\mathrm{mg} \cdot \mathrm{L}^{-1}\right)\end{array}$ \\
\hline Ácido fórmico & 5,0 & 15,0 \\
\hline Ácido acético & 5,0 & 15,0 \\
\hline Ácido propiônico & 5,0 & 15,0 \\
\hline Ácido isobutírico & 5,0 & 15,0 \\
\hline Ácido butírico & 5,0 & 15,0 \\
\hline Ácido isovalérico & 6,25 & 18,75 \\
\hline Ácido valérico & 10,0 & 30,0 \\
\hline
\end{tabular}

Tabela 4 - Coeficientes de correlação linear obtidos para cada ácido graxo volátil e usado no teste de linearidade (faixa de trabalho).

\begin{tabular}{|lc|}
\hline Analito & Coeficiente de correlação linear $\left(\mathbf{R}^{2}\right)$ \\
\hline Ácido fórmico & 0,9986 \\
\hline Ácido acético & 0,9974 \\
\hline Ácido propiônico & 0,9967 \\
\hline Ácido isobutírico & 0,9958 \\
\hline Ácido butírico & 0,9952 \\
\hline Ácido isovalérico & 0,9934 \\
\hline Ácido valérico & 0,9962 \\
\hline
\end{tabular}


Os dados apresentados em Cerqueira et al. (2011) mostram coeficientes de correlação linear para os ácidos acético, propiônico e butírico ligeiramente superiores aos aqui relatados (iguais a 0,999 para o acético e propiônico e 0,996 para o butírico), diferença que não representa qualquer relevância, ao se comparar os dois métodos.

\section{Precisão (repetitividade)}

A repetitividade expressa a fidelidade obtida nas mesmas condições operacionais, aplicadas em um curto intervalo de tempo (LANÇAS, 2004). Os valores de coeficiente de variação (CV) para as áreas dos picos cromatográficos obtidos para a mistura de AGV numa concentração de $200 \mathrm{mg} \cdot \mathrm{L}^{-1}$ estão expressos na Tabela 5. Valores de CV de até 20\% são aceitáveis (INMETRO, 2006); portanto, pode-se afirmar que o método é preciso para todos os AGV, uma vez que o maior coeficiente de variação obtido no ensaio foi de 1,64\% para o ácido isovalérico.

O trabalho de Cerqueira et al. (2011) avalia a repetitividade em um método para análise de três AGV (ácidos acético, propiônico e butírico), usando uma coluna de fase reversa (Waters Spherisorb ODS2, 150x4,6 mm, $5 \mu \mathrm{m}$ ). Seus resultados demonstram que o coeficiente de variação para o ácido propiônico ficou acima de 17\%. O método aqui apresentado, portanto, demonstra melhor repetitividade.

\section{Efeito de matriz}

O efeito de matriz atesta se os componentes da amostra interferem na determinação dos analitos de interesse. O método da adição padrão foi o escolhido para avaliação do efeito de matriz, uma vez que é praticamente impossível obter um efluente anaeróbio isento dos ácidos orgânicos. Para tanto, comparou-se os coeficientes angulares das curvas de calibração construídas na ausência de matriz com aquelas obtidas com amostras de efluente anaeróbio fortificadas com AGV, sendo o critério adotado como uma diferença menor ou igual a 5\% (LANÇAS, 2004).

A Tabela 6 apresenta a diferença percentual entre os coeficientes angulares para as amostras com e sem fortificação de AGV.

Os resultados obtidos mostram que, à exceção do ácido isobutírico em que o efeito de matriz pareceu mais pronunciado, o método utilizado foi pouco susceptível à interferência causada pelos componentes da amostra (efluente anaeróbio). Os dados mostram ainda que a matriz interferiu pouco na resposta do ácido propiônico, no qual se observou variação percentual de coeficiente angular de apenas $1,6 \%$.

Tabela 5 - Áreas dos picos cromatográficos obtidos para cada analito (200 mg. $\left.\mathrm{L}^{-1}\right)$ presentes na mistura de ácidos graxos voláteis e cálculo dos parâmetros de repetitividade (desvio padrão, coeficiente de variação) do método.

\begin{tabular}{|lcccccccc} 
& Fórmico & Acético & Propiônico & Isobutírico & Butírico & Isovalérico & Valérico \\
& 617,16 & 378,12 & 354,19 & 452,32 & 329,18 & 341,08 & 302,07 \\
& 618,82 & 378,76 & 351,56 & 451,13 & 329,56 & 343,06 & 295,57 \\
& 613,37 & 375,59 & 350,74 & 452,72 & 329,27 & 337,11 & 298,21 \\
& 625,80 & 385,51 & 355,81 & 456,45 & 331,33 & 352,65 & 299,77 \\
& 616,94 & 374,00 & 349,25 & 453,76 & 331,00 & 343,26 & 297,11 \\
\hline DP & 627,55 & 389,95 & 358,84 & 461,63 & 339,23 & 351,47 & 305,69 \\
\hline Média & 626,00 & 379,56 & 354,52 & 455,96 & 331,36 & 347,98 & 294,32 \\
\hline CV (\%) & 5,55 & 5,62 & 3,29 & 3,55 & 3,51 & 5,68 & 3,93 \\
\hline
\end{tabular}

DP: desvio padrão; CV: coeficiente de variação.

Tabela 6 - Coeficientes angulares das curvas analíticas e diferenças percentuais, com e sem efeito de matriz, para teste de seletividade.

\begin{tabular}{|c|c|c|c|c|}
\hline Analito & Na matriz* & Em água destilada & Diferença absoluta & Diferença percentual (\%) \\
\hline Ácido fórmico & 0,8643 & 0,8868 & $-0,0225$ & $-2,5$ \\
\hline Ácido acético & 0,5598 & 0,5761 & $-0,0163$ & $-2,8$ \\
\hline Ácido propiônico & 0,5397 & 0,5482 & $-0,0085$ & $-1,6$ \\
\hline Ácido isobutírico & 0,6849 & 0,7934 & $-0,1085$ & $-13,7$ \\
\hline Ácido butírico & 0,5377 & 0,5607 & $-0,023$ & $-4,1$ \\
\hline Ácido isovalérico & 0,5388 & 0,5139 & 0,0249 & 4,8 \\
\hline Ácido valérico & 0,4713 & 0,4812 & $-0,0099$ & $-2,1$ \\
\hline
\end{tabular}


Esses resultados se equiparam com os obtidos por Cerqueira et al. (2011), onde é demonstrado que o efeito de matriz para os ácidos acético, propiônico e butírico foram de, respectivamente, $1,4,-3,9$ e $-4,1 \%$. Todos esses resultados são bem abaixo de $5 \%$, valor considerado de baixo efeito de matriz (ECONOMOU et al., 2009 apud CERQUEIRA et al., 2011).

\section{Exatidão}

A exatidão expressa a concordância entre o valor encontrado e o valor aceito como referência. A análise de exatidão pode ser realizada por meio de ensaios de recuperação, sendo essa realizada em pelo menos três diferentes concentrações, por exemplo, próximo ao limite de detecção, próximo à concentração máxima permissível e em uma concentração próxima à média da faixa de uso do método. Outro método é o da adição padrão (RIBANI et al., 2004), adotado neste estudo.

O método de adição padrão foi adotado em função de ser impossível preparar um branco da matriz (efluente anaeróbio) sem os analitos de interesse. Para este ensaio, padrões de $200 \mathrm{mg} . \mathrm{L}^{-1}$ de cada ácido foram adicionados ao efluente anaeróbio e as concentrações reais foram calculadas a partir da curva de calibração. Na Tabela 7 , são apresentados os dados de exatidão calculados.

Tabela 7 - Exatidão do método para cada analito presente na mistura de ácidos graxos voláteis.

\begin{tabular}{lc|}
\hline Analito & Exatidão (\%) \\
\hline Ácido fórmico & 95,19 \\
\hline Ácido acético & 93,04 \\
\hline Ácido propiônico & 95,21 \\
\hline Ácido isobutírico & 85,39 \\
\hline Ácido butírico & 94,27 \\
\hline Ácido isovalérico & 104,24 \\
\hline Ácido valérico & 97,10 \\
\hline
\end{tabular}

Tabela 8 - Valores dos coeficientes angulares obtidos a partir das curvas analíticas e usadas na avaliação da sensibilidade do método.

\begin{tabular}{lc|}
\hline Analito & Coeficiente angular \\
\hline Ácido valérico & 1,49 \\
\hline Ácido butírico & 1,72 \\
\hline Ácido propiônico & 1,76 \\
\hline Ácido isovalérico & 1,77 \\
\hline Ácido acético & 1,89 \\
\hline Ácido isobutírico & 2,30 \\
\hline Ácido fórmico & 3,03 \\
\hline
\end{tabular}

O método utilizado se mostrou exato para todos os ácidos, uma vez que os valores de porcentagem média ficaram compreendidos entre 85 e 104\%, valores semelhantes aos reportados por Cerqueira et al. (2011), os quais foram de 89 a 102\%. Segundo Lanças (2004), a faixa média aceitável para avaliação de exatidão por ensaios de recuperação é de 70 a $120 \%$.

\section{Sensibilidade}

A sensibilidade de um método indica sua capacidade de discriminar, com uma fidelidade estabelecida, concentrações próximas de um analito. A sensibilidade pode ser determinada por intermédio da inclinação da curva analítica, uma vez que quanto maior a absortividade da substância, maior o coeficiente angular, mais sensível é o método. Para cada curva analítica construída para a avaliação da linearidade, foi avaliado o coeficiente angular obtido a partir da análise regressão linear, o que permite comparar a sensibilidade do método para cada AGV. A Tabela 8 sistematiza a informação dos coeficientes angulares obtidos com a regressão linear.

Observa-se que o método empregado é mais sensível para o ácido fórmico $(3,03)$ e bem menos sensível para o ácido valérico $(1,49)$. De fato, esta observação confirma os diferentes comportamentos dos analitos na determinação dos LD e LQ, quando foi verificado que o ácido valérico era o composto determinante, expressando a pior condição. Como o ácido valérico é menos sensível ao método de análise, a sua detecção e quantificação é desfavorecida comparativamente aos demais AGV da mistura.

\section{Conclusões}

O método de cromatografia líquida de alta eficiência proposto para análise de sete AGV (ácidos fórmico, acético, propiônico, butírico, isobutírico, valérico e isovalérico) em amostras de efluentes anaeróbios foi devidamente validado segundo os critérios de limite de detecção, limite de quantificação, faixa de trabalho, linearidade, precisão (repetitividade), sensibilidade, seletividade e exatidão.

O LD calculado ficou entre 5,0 e 10,0 mg. $\mathrm{L}^{-1}$, e o LQ entre 15,0 e 30,0 mg. $\mathrm{L}^{-1}$. A linearidade neste intervalo foi demonstrada, na faixa de 25,00 a 1000,0 mg. $\mathrm{L}^{-1}$. O método apresentou boa repetitividade uma vez que a pior condição, obtida para o ácido isovalérico, resultou em coeficiente de variação de 1,64\%. Além disso, o método apresentou boa seletividade para os sete AGV testados, à exceção do ácido isobutírico, para qual o efeito de matriz pareceu mais pronunciado. O efeito de matriz pareceu ser menos interferente para o ácido propiônico. A exatidão do método também foi comprovada e variou de 85 a 104\%. Sendo assim, as condições operacionais adotadas para as análises cromatográficas se mostraram adequadas e válidas para a determinação quantitativa de AGV em amostras de efluentes anaeróbios. 


\section{Referências}

ÁBALOS, M.A.; BAYONA, J.M.; PAWLISZYN, J. (2000) Development of a headspace solid-phase microextraction procedure for the determination of free volatile fatty acids in waste waters. Journal of Chromatography $A$, v. 873 , p. $107-115$

AGÊNCIA NACIONAL DE VIGILÂNCIA SANITÁRIA (ANVISA). 2003. Guia para validação de métodos analíticos e bioanalíticos. Resolução RE n 899 de 29/05/2003. Brasília (DF): Diário Oficial da República Federativa do Brasil.

AQUINO, S.F.; CHERNICHARO, C.A. (2005) Acúmulo de ácidos graxos voláteis (AGVs) em reatores anaeróbios sob estresse: causas e estratégias de controle. Engenharia Sanitária Ambiental, v. 10, n. 2, p. 152-161.

AQUINO, S.F.; STUCKEY, D.C. (2004) Soluble Microbial Product formation in anaerobic chemostats in the presence of toxic compounds. Water Research, v. 38, n. 2, p. 255-266

CERQUEIRA, M.B.R.; DIAS, A.N.; CALDAS, S.S.; SANTANA, F.B.; D'OCA, M.G.M.; PRIMEL, E.G. (2011) Validação de método para determinação de ácidos orgânicos voláteis em efluentes de reatores anaeróbios empregando cromatografia líquida. Química Nova, v. 34, n. 1, p. 156-159.

CLARK, T.J.; BUNCH, J.E. (1997) Organic Acids in Tobacco. The Journal of Chromatographic Science, v. 35, n. 5, p. 209-212.

CORRÊA, C.A.R (2009). Efeito da adição de extrato de levedura na degradação de corante azo em reator UASB. 2009, 112 f. Dissertação (Mestrado do Programa de Pós-Graduação em Engenharia Ambiental) - Universidade Federal de Ouro Preto, Ouro Preto.

EILERSEN, A.M.; HENZE, M.; KLOFT, L. (1995) Effect of volatile fatty acids and trimethylamine on denitrification in activated sludge. Water Research, v. 29, p. 1259-1266.

HARTMANN, C.; SMEYERS-VERBEKE, J.; MASSART, D.L.; MCDOWALL, R.D. (1998) Validation of bioanalytical chromatographic methods (review). Journal of Pharmaceutical and Biomedical Analysis, v. 17, p. 193-218.

INSTITUTO NACIONAL DE METROLOGIA, NORMALIZAÇÃO E QUALIDADE INDUSTRIAL (INMETRO). Orientação sobre validação de métodos de ensaios químicos. Documento orientativo DOQCGCRE-008. 35 p.

LANÇAS, F.M. (2004) Validação de métodos cromatográficos de análise. São Carlos: Ed. RiMa. 62 p.

MANNI, G.; CARON, F. (1995) Calibration and determination of volatile fatty acids in waste leachates by gas chromatography. Journal of Chromatography A, v. 690, p. 237-242.
MESQUITA, P.L.; XAVIER, A.L.P.; AFONSO, R.C.F.; AQUINO, S.F. (2010) Produção de compostos microbianos solúveis em reatores aeróbio e anaeróbio de mistura completa. In Congresso Brasileiro de Engenharia Sanitária e Ambiental, 25 Trabalhos Técnicos. Recife.

MORAES, E.M.; FORESTI, E.; ZAIAT, M.; ADORNO, M.A.T. (2001) Determinação de ácidos voláteis por cromatografia gasosa em efluentes de reatores anaeróbios. In: CHERNICHARO, C.A.L. (coord.). Pós-tratamento de efluentes de reatores anaeróbios: aspectos metodológicos. Belo Horizonte: Prosab. p. 35-42.

RANDALL, A.A.; BENEFIELD, L.D.; HILL, W.E.; NICOL, J.P.; BOMAN G.K.; JING, S.R. (1997) The effect of volatile fatty acids on enhanced biological phosphorus removal and population structure in anaerobic/ aerobic sequencing batch reactors. Water Science and Technology, v. 35 , n. 1 , p. $153-60$

RIBANI, M.; BOTOLLI, C.B.; COLLINS, C.H.; JARDIM, I.C.; MELO, L.F. (2004) Validação de métodos cromatográficos e eletroforéticos. Química Nova, v. 27, n. 5, p. 771-780

RIBAS, M.M.F.; MORAES, E.M.; FORESTI, E. (2007) Avaliação da acurácia de diversos métodos para determinação de ácidos graxos voláteis e alcalinidade a bicarbonato para monitoramento de reatores anaeróbios. Engenharia Sanitária Ambiental, v. 12, n. 3, p. 240-246.

RITTMANN, B.E.; MCCARTY, P.L. (2001) Environmental Biotechnology: principles and applications. Nova lorque: McGraw Hill., 768 p.

SANTOS, A.R.L.; AQUINO, S.F.; CARVALHO, C.F.; VIEIRA, L.A.; GONTIJO, E.S.J. (2010) Caracterização e tratabilidade biológica dos efluentes líquidos gerados em cabines de pintura de uma indústria moveleira. Engenharia Sanitária Ambiental, v. 15, n. 4, p. 357-366.

SPEECE, R.E. (1996) Anaerobic biotechnology for industrial wastewaters. Nashville (EUA): Archae Press. 416 p.

VOOLAPALLI, R.K.; STUCKEY, D.C. (2001) Hydrogen production in anaerobic reactors during shock loads - Influence of formate production and $\mathrm{H}-2$ kinetics. Water Research, v. 35, n. 7, p. 1831-1841.

ZAHER, U., MOUSSA, M.S., WIDYATMIKA, I.N., VAN DER STEEN, P., GIJZEN, H.J., VANROLLEGHEM, P.A. (2006) Modelling anaerobic digestion acclimatisation to a biodegradable toxicant: application to cyanide. Water Science and Technology, v. 54, n. 4, p. 129-137.

ZURIGUEL, V.; CAUSSE, E.; BOUNERY, J.D.; NOUADJE, G.; SIMEON, N.; NERTZ, M.; SALVAYRE, R.; COUDERC, F. (1997) Short chain fatty acids analysis by capillary electrophoresis and indirect UV detection or laserinduced fluorescence. Journal of Chromatography A, v. 781, p. 233-238. 